\title{
Serum Insulin-Like Growth Factor I Reference Values for an Automated Chemiluminescence Immunoassay System: Results from a Multicenter Study
}

\author{
Georg Brabant ${ }^{a}$ Alexander von zur Mühlen ${ }^{a}$ Christian Wüster ${ }^{b}$ Michael B. Ranke ${ }^{c}$ \\ Jürgen Kratzsch $^{d}$ Wieland Kiess $^{d}$ Jean-Marie Ketelslegers ${ }^{e}$ Lars Wilhelmsen ${ }^{f}$ \\ Lena Hulthén ${ }^{f}$ Bernhard Sallerg Anders Mattssong Jürgen Wilde ${ }^{h}$ Rudolf Schemer ${ }^{h}$ \\ Peter Kann ${ }^{i}$ On behalf of the German KIMS Board \\ aDepartment of Gastroenterology, Hepatology and Endocrinology, Medizinische Hochschule, Hannover, Germany; \\ ${ }^{b}$ Department of Internal Medicine I, Endocrinology and Metabolism, University Medical Clinic, Heidelberg, Germany; \\ cPediatric Endocrinology Section, University Children's Hospital, Tübingen, Germany; \\ ${ }^{\mathrm{d} C h i l d r e n ' s ~ H o s p i t a l ~ a n d ~ I n s t i t u t e ~ f o r ~ L a b o r a t o r y ~ M e d i c i n e, ~ U n i v e r s i t y ~ o f ~ L e i p z i g, ~ G e r m a n y ; ~}$ \\ eDepartment of Internal Medicine, School of Medicine, Catholic University of Louvain, Brussels, Belgium; \\ fGöteborg University, Göteborg, Sweden; gPharmacia Corp., Erlangen, Germany and Stockholm, Sweden; \\ hNichols Institute Diagnostica, Bad Vilbel, Germany; 'Department of Endocrinology and Diabetes, \\ Philipps University, Marburg, Germany
}

\section{Key Words}

IGF-I · Chemiluminesce assay · Reference range •

Growth hormone

\begin{abstract}
Background: Analysis of insulin-like growth factor I in serum (S-IGF-I) is an integral component in the diagnosis of $\mathrm{GH}$-related disorders and is going to be of interest in the diagnosis and follow-up of many disorders. The objective of the present study was to develop cross-sectional reference values for S-IGF-I measured by an automated chemiluminescence immunoassay (Nichols Advantage $\left.{ }^{\circledR}\right)$. Methods: The study included samples from 3,961 healthy subjects $(2,201$ males, 1,760 females $)$ aged 1 month to 88 years. Six laboratories were involved in this study and the samples were analyzed by one of seven automated immunoassay systems run in these laboratories. For data analysis, polynomial age and sex-specific models were fitted after transformation of S-IGF-I
\end{abstract}

\section{KARGER}

Fax +4161306 1234 E-Mail karger@karger.ch www.karger.com

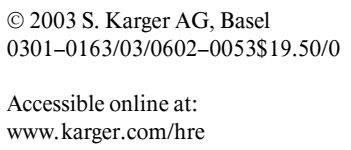

values. Results: The results show the well-known age dependency of S-IGF-I levels. At ages $<20$, higher S-IGF-I levels were seen in girls with an estimated mean peak of $410 \mu \mathrm{g} / \mathrm{l}$ at age 14 and an estimated mean peak of $382 \mu \mathrm{g} / \mathrm{l}$ at age 16 in boys. Thereafter, a rapid decrease was seen to approximately 25 years of age, followed by a slow age-dependent decrease. In adulthood, S-IGF-I in males were slightly, but significantly higher than in females. It could be shown that the mean values of some reference sample subgroups differed significantly from the total mean. However, the multicenter approach used in this study reduces the impact of systematic population, sample handling and laboratory differences on the calculated reference mean. Conclusion: The present study establishes age- and sex-specific reference values for a fully automated immunoassay system based on a large population of healthy subjects. The established reference values may be used for this immunoassay system in different laboratories provided that the systematic difference between systems is low.

Copyright $\odot 2003$ S. Karger AG, Base

Prof. Dr. med. Georg Brabant

Hannover Medical School

Department of Gastroenterology, Hepatology and Endocrinology

Carl-Neuberg-Strasse 1, DE-30625 Hannover (Germany)

Tel. +49 511 5326528, Fax +49511 5323825, E-Mail brabant.georg@mh-hannover.de 


\section{Introduction}

Analysis of insulin-like growth factor I in serum (SIGF-I) has become an integral component in the diagnosis of growth hormone $(\mathrm{GH})$-related disorders in children and adults [1-3]. Moreover, S-IGF-I is used for dose adjustment of GH replacement therapy in children and adults [4], and is suggested as the most reliable component for monitoring the success of therapeutic interventions in acromegaly [5, 6]. In addition to these applications in GH-related disorders, recent studies have focused on a possible relation between S-IGF-I levels and the risk for certain malignancies as well as on a prognostic significance of S-IGF-I levels in patients with malignant diseases [7,8]. These developments indicate that analysis and interpretation of S-IGF-I levels are no longer the mainstay of a few specialized laboratories but that S-IGF$\mathrm{I}$ is going to be a component that is widely used in the diagnosis and follow-up of many disorders.

It is thus imperative to achieve uniform interpretations of S-IGF-I levels by improving the standardization and inter-laboratory comparability of S-IGF-I analysis procedures $[9,10]$. This includes the establishment of normative data in representative populations by valid immunoassays and by considering non-GH-related factors that are known to influence S-IGF-I concentrations like age and sex.
The objective of the present study was to develop cross-sectional reference values for S-IGF-I measured by a widely used automated chemiluminescence immunoassay (Nichols Advantage ${ }^{\circledR}$ ) in a normal population of children, adolescents and adults.

\section{Subjects and Methods}

\section{Subjects}

S-IGF-I has been determined in samples from 3,961 healthy subjects aged 1 month to 88 years. In a multicenter study design, six laboratories were involved, four in Germany, one in Belgium and one in Sweden. 1,469 samples were from children and adolescents (745 females and 724 males) aged up to 19.9 years, 2,492 samples were from adults (1,015 females and 1,477 males) aged 20 years or more. Table 1 gives the sex and age distribution of the subjects included.

Subjects were either selected from blood-bank sampling, study populations or clinical routine. Informed consent was obtained from the patients or the patients' parents. The study protocol had been approved by the responsible local ethics committee.

Subjects with diseases, in particular renal diseases, liver diseases, malignant disorders, diabetes mellitus and diseases of the pituitary gland, were excluded by medical history, physical examination and routine laboratory tests. In addition, adult subjects with a body mass index $>30$ and $<18 \mathrm{~kg} / \mathrm{m}^{2}$ were excluded from the study.

All samples were collected in tubes not containing any anticoagulants and were routinely processed with a maximum time interval of 60 min between sampling and freezing. Serum was separated and stored frozen at -20 or $-70^{\circ} \mathrm{C}$ until analysis. Samples were assayed

Table 1. Age and sex distribution of the study population

\begin{tabular}{|c|c|c|c|c|c|c|c|c|c|c|c|c|}
\hline \multirow{2}{*}{$\begin{array}{l}\text { Children and } \\
\text { adolescents }\end{array}$} & \multicolumn{12}{|c|}{ Age, years } \\
\hline & $0-1$ & $2-3$ & $4-5$ & $6-7$ & $8-9$ & $10-11$ & $12-13$ & $14-15$ & $16-17$ & $18-19$ & & \\
\hline Males & 31 & 41 & 28 & 24 & 73 & 75 & 53 & 307 & 58 & 34 & & \\
\hline Females & 12 & 36 & 28 & 19 & 66 & 127 & 48 & 273 & 84 & 52 & & \\
\hline Total & 43 & 77 & 56 & 43 & 139 & 202 & 101 & 580 & 142 & 86 & & \\
\hline \multirow[t]{2}{*}{ Adults } & \multicolumn{12}{|c|}{ Age, years } \\
\hline & $20-24$ & $25-29$ & $30-34$ & $35-39$ & $40-44$ & $45-49$ & $50-54$ & $55-59$ & $60-64$ & $65-69$ & $70-74$ & $75-88$ \\
\hline Males & 119 & 167 & 182 & 168 & 176 & 152 & 121 & 134 & 128 & 68 & 40 & 22 \\
\hline Females & 153 & 109 & 112 & 124 & 115 & 113 & 85 & 64 & 67 & 30 & 23 & 20 \\
\hline Total & 272 & 276 & 294 & 292 & 291 & 265 & 206 & 198 & 195 & 98 & 63 & 42 \\
\hline \multicolumn{13}{|l|}{ All subjects } \\
\hline Males & 2,201 & & & & & & & & & & & \\
\hline Females & 1,760 & & & & & & & & & & & \\
\hline Total & 3,961 & & & & & & & & & & & \\
\hline
\end{tabular}


within 2 months after sampling. Grossly hemolytic, lipemic or icteric samples were excluded. Prior to S-IGF-I determination the samples were allowed to come to room temperature.

\section{Analysis of $S-I G F-I$}

S-IGF-I concentrations were determined by a fully automated, two-site chemiluminescent immunoassay (Nichols Advantage ${ }^{\circledR}$; Nichols Institute Diagnostics, San Clemente, Calif., USA). In this system the antibody to the C-terminal $62-70$ amino acid sequence is biotinylated for capture and the antibody to the amino acid sequences of 1-23 and 42-61 is labeled with acridinium ester for detection. Subject samples are acidified to separate S-IGF-I from IGFbinding proteins. The acidified samples are incubated with the biotinylated capture antibody in the presence of excess IGF-II and acridinium ester-labeled antibody. This displacement method was found to be very accurate based on a recent comparison study with different IGF-I assays [11]. After the initial incubation period, strepavidincoated magnetic particles are added to the reaction mixture. Free labeled antibody is then separated from the labeled antibody bound to the magnetic particles by aspiration and subsequent washing, while a strong magnetic force keeps the magnetic particles in the well. An acid hydrogen peroxide solution and a sodium hydroxide solution are added to the well to initiate the chemiluminescence reaction.

The assay has been calibrated against the World Health Organization International Reference Reagent 87/518.

A single S-IGF-I analysis result was obtained from each subject involved. The samples were analyzed by any of the seven systems used for this study. The time period of analysis was for six of the seven systems between December 1999 and June 2001. The six systems were run by five laboratories (UCL Brussels, University of Hanover, University of Leipzig, University of Tübingen, and Nichols Diagnostica, Bad Vilbel, Germany). To ensure proper instrument performance and to allow the comparison between runs, instru- ments and laboratories, IGF-I control samples (Nichols Institute Diagnostics, San Clemente, Calif., USA) were analyzed in each batch of reference samples. All runs with one or more controls out of given ranges (mean $\pm 2 \mathrm{SD}$ ) were recalibrated and recalculated using the 4-PL logistics of the system (Nichols Advantage ${ }^{\circledR}$ software, version 92.56) until all controls were in range.

One lot of control samples (three levels) was used in these five laboratories during the entire period December 1999 to June 2001. For control level 1 (target: 60) a mean value (SD) of $58(3.3) \mu \mathrm{g} / 1$ was found ( $\mathrm{n}=69)$; for control level 2 (target 259) $259(16) \mu \mathrm{g} / \mathrm{l}(\mathrm{n}=71)$, and for control level 3 (target 546) $539(36) \mu \mathrm{g} / \mathrm{l}(\mathrm{n}=74)$. Table 2 gives the results of the control samples for each of the six different analysis systems.

The seventh system in laboratory No. 6 did not use the same lot of control samples and the selected reference population was analyzed during April 2002. For control level 1 (target: 56) a mean value (SD) of $44(4.0) \mu \mathrm{g} / \mathrm{l}$ was found $(\mathrm{n}=6)$, corresponding figures for control level 2 (target 250) were $221(11) \mu \mathrm{g} / \mathrm{l}(\mathrm{n}=6)$, and for control level 3 (target 488) $476(26) \mu \mathrm{g} / \mathrm{l}(\mathrm{n}=6)$.

\section{Statistical Analysis}

The mean and variance of population S-IGF-I-values are dependent on age and maybe on sex. Moreover, the distribution of IGF-I values is skewed (fig. 1). After inspection of the data we decided to fit polynomial models. In order to find a scale with as constant variance as possible for the observations, different transformations of the SIGF-I values were compared (log, square root, and powers between 0.2 and $0.7(0.5=$ square root $))$. For a given transformation of $\mathrm{S}$ IGF-I different smooth functions of age of the form

$$
\begin{aligned}
& f(\text { age })=b_{0}+b_{11} \text { age }+b_{12} a e^{2}+b_{13} a g e^{3}+b_{23} i\left(a g e-x_{1}\right)^{3}+ \\
& b_{33}\left(\text { age }-x_{2}\right)^{3}+b_{14} i\left(a g e-x_{2}\right)^{4}
\end{aligned}
$$

Table 2. S-IGF-I values $(\mu \mathrm{g} / \mathrm{l})$ in three control samples as measured by six different instruments during the period December 1999 to June 2001

\begin{tabular}{llrlllll}
\hline Control & $\begin{array}{l}\text { Instrument } \\
\text { No. }\end{array}$ & $\mathrm{n}$ & Mean & Min. & Max. & SD & $\mathrm{CV}, \%$ \\
& & & & & & & \\
\hline Level 1 & 1 & 23 & 58.7 & 55.0 & 65.0 & 2.4 & 4.1 \\
Target 60 & 2 & 8 & 56.0 & 52.8 & 60.9 & 2.5 & 4.4 \\
& 3 & 31 & 59.2 & 52.5 & 65.4 & 3.5 & 5.9 \\
& 4 & 1 & 63.0 & - & - & - & - \\
& 5 & 3 & 57.6 & 56.8 & 59.2 & 1.1 & 1.9 \\
& 6 & 3 & 54.8 & 52.4 & 56.6 & 1.8 & 3.2 \\
\hline Level 2 & 1 & 23 & 261.5 & 230.1 & 282.9 & 15.0 & 5.7 \\
Target 259 & 2 & 5 & 256.0 & 225.4 & 279.8 & 18.1 & 7.1 \\
& 3 & 31 & 257.7 & 229.2 & 286.3 & 14.8 & 5.7 \\
& 4 & 2 & 257.0 & 249.0 & 265.0 & 8.0 & 3.1 \\
& 5 & 5 & 258.5 & 248.6 & 272.5 & 8.3 & 3.2 \\
& 6 & 5 & 266.4 & 253.2 & 277.8 & 10.0 & 3.8 \\
\hline Level 3 & 1 & 23 & 537.1 & 453.2 & 578.4 & 34.8 & 6.5 \\
Target 546 & 2 & 8 & 506.3 & 432.0 & 576.4 & 44.8 & 8.8 \\
& 3 & 31 & 541.9 & 470.0 & 628.2 & 52.9 & 9.8 \\
& 4 & 2 & 592.5 & 556.0 & 629.0 & 36.5 & 6.2 \\
& 5 & 5 & 527.2 & 500.2 & 558.8 & 19.4 & 3.7 \\
& 6 & 5 & 543.5 & 496.9 & 565.5 & 25.6 & 4.7 \\
\hline
\end{tabular}


Fig. 1. S-IGF-I as a function of age. The figure gives the individual values of the 3,961 healthy subjects $(2,201$ males, 1,760 females) as well as the curves for the fitted mean, $\pm 1 \mathrm{SD}$ and $\pm 2 \mathrm{SD}$ functions given by $[\mathrm{f}($ age $) \pm \mathrm{kSD})]^{2.5} \mathrm{k}=0,1,2$. (a all subjects; b males; c females).
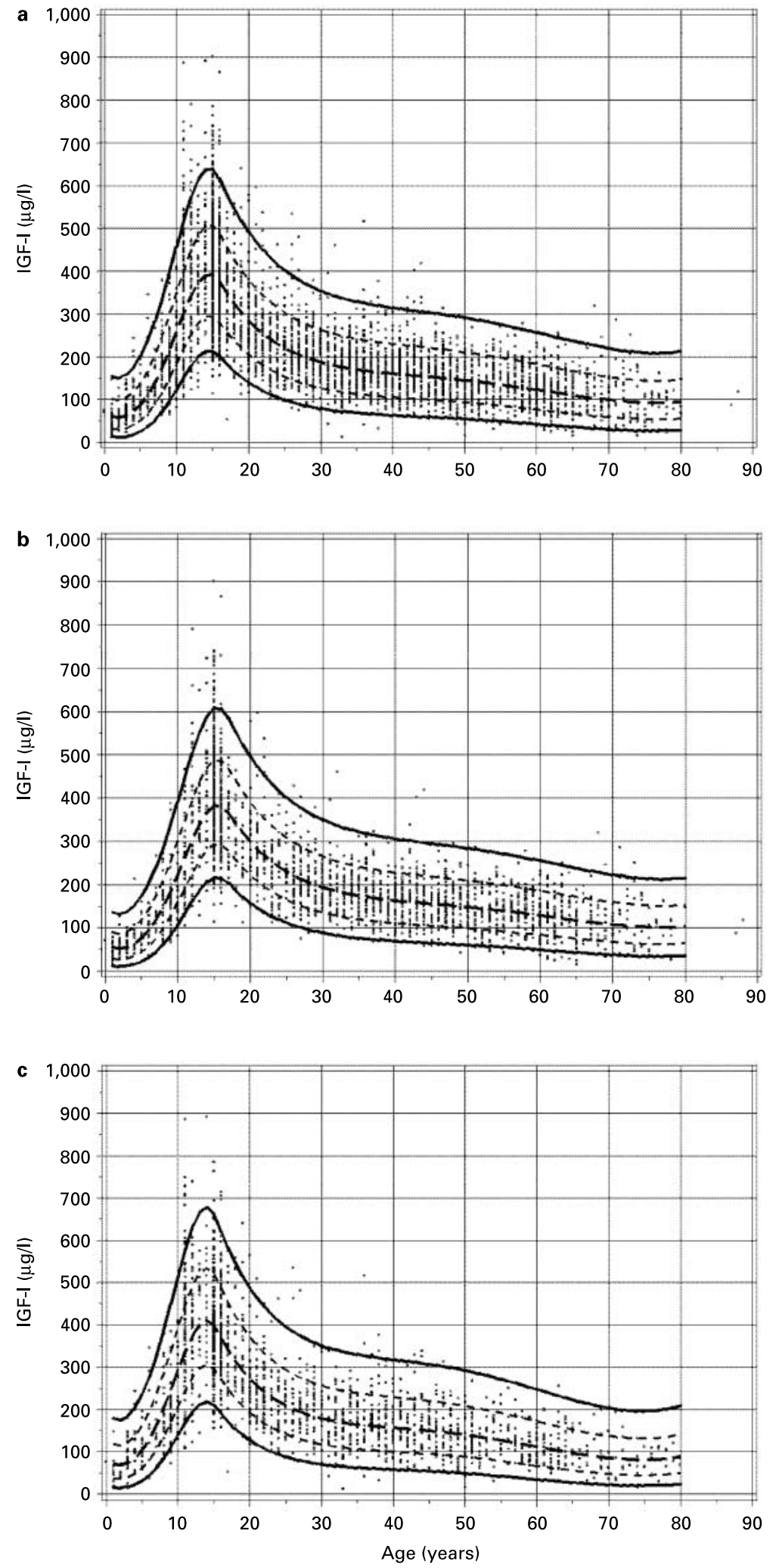
where ${ }_{i}\left(\right.$ age $\left.-x_{j}\right)$ is 0 if age $<x_{j}$ and $\left(\right.$ age $\left.-x_{j}\right)$ if age $\geq x_{j}\left(j=1.2\right.$, and $x_{1}$ $<\mathrm{x}_{2}$ ) were compared. Different values on $\mathrm{x}_{\mathrm{j}}$ were compared for adjusting location of peak and curvature. The model that reached the highest explanation in terms of coefficient of determination, $\mathrm{R}^{2}$, and where the transformed S-IGF-I observations 'best' followed a normal distribution around the fitted function of age was chosen [12]. In the final model, gender was incorporated and its contribution tested. Gender was coded 1 if female and 0 if male. Potential interaction between age and gender was tested by gender times ${ }_{i}($ age $<20)$, where i $($ age $<20)=1$ if age $<20$ years, otherwise 0 . Reference curves for S-IGF-I were approximated by $[\mathrm{f}(\mathrm{age}) \pm \mathrm{kSD}]^{1 / \mathrm{P}}$, where $\mathrm{P}$ is the power of transformation of S-IGF-I and $\mathrm{k}$ number of model based standard deviations (SD). For the logarithmic transformation [f(age) \pm $\mathrm{kSD}$ ] was exponentiated.

In an additional analysis, a random intercept model was fitted assuming the polynomial structure $\mathrm{f}$ (age, gender) but at different levels for each lab. The random intercept model is structured so that each lab has its own intercept. These intercepts are formulated as deviations from the 'population mean'. In graphical terms it means that the polynomial structure is represented at different levels according to [population mean at a given age + lab-specific intercept deviation $]^{1 / P}$. In hypothesis testing the deviations are assumed to follow a normal distribution with mean $\mu=0$ and variance $\sigma^{2}$.

PROC REG and PROC MIXED in SAS software were used for the statistical analyses (Statistical Analysis System, version 8.2, SAS Institute, Cary, N.C., USA).

\section{Results}

Figure 1 shows plots of S-IGF-I values in 3,961 healthy subjects versus age of the subjects. Scattergrams are given for the whole study population (fig. 1a), as well as for males (fig. 1b) and females (fig. 1c) separately. Females appear to have higher values than males at ages $<20$. The peak also occurs 1-2 years earlier (13-14 years among girls and 15-16 years among boys). After 20 years of age, females have slightly lower values.

The transformation that best conformed these S-IGF-I data to the normal distribution was the power 0.4. Mean value, SD and reference limits have been calculated on the IGF-I ${ }^{0.4}$ scale and then back transformed, i.e. raised to the power of 2.5. The IGF-I ${ }^{0.4}$ scale should also be used when standard deviation score (SDS) is calculated: IGF-I $\mathrm{SDS}=\left(\mathrm{IGF}-\mathrm{I}^{0.4}-\mathrm{f}(\right.$ age $\left.)\right) / \mathrm{SD}$.

The age-specific model fitted to all data shows - after a plateau in the first years of life - a rapid increase of SIGF-I up to a peak at around 14-16 years of age. After the peak, S-IGF-I decreases rapidly to approximately 25 years of age. From there a slow decrease begins persisting up to

Table 3. Parameter estimates with standard errors, $\mathrm{SD}$ and $\mathrm{R}^{2}$ for three fitted polynomial models (see details in Methods and Results sections)

\begin{tabular}{|c|c|c|c|c|c|c|c|c|c|}
\hline & \multicolumn{3}{|c|}{ Model 1a: Males + females } & \multicolumn{3}{|l|}{ Model 1b: Males } & \multicolumn{3}{|l|}{ Model 1b: Females } \\
\hline & effect estimate: b & $\operatorname{se}(b)$ & $\mathrm{p}$ value & effect estimate: $b$ & se(b) & $\mathrm{p}$ value & Effect estimate: $b$ & se(b) & $\mathrm{p}$ value \\
\hline \multicolumn{10}{|l|}{$\mathrm{f}($ age $)$} \\
\hline intercept & 5.44721 & 0.21 & $<0.0001$ & 5.24323 & 0.23 & $<0.0001$ & 5.79754 & 0.36 & $<0.0001$ \\
\hline age & -0.43311 & 0.08 & $<0.0001$ & -0.41428 & 0.09 & $<0.0001$ & -0.45049 & 0.14 & 0.0015 \\
\hline $\mathrm{age}^{2}$ & 0.13725 & 0.01 & $<0.0001$ & 0.12330 & 0.01 & $<0.0001$ & 0.14574 & 0.015 & $<0.0001$ \\
\hline age3 & -0.005612 & 0.0003 & $<0.0001$ & -0.0047353 & 0.0003 & $<0.0001$ & -0.00618 & 0.0005 & $<0.0001$ \\
\hline i (age-15) $)^{3}$ & 0.027046 & 0.001 & $<0.0001$ & & & & & & \\
\hline i (age-17) & -0.021702 & 0.001 & $<0.0001$ & & & & & & \\
\hline i (age-17) & 0.0000018566 & $2.31 \mathrm{E}-7$ & $<0.0001$ & & & & & & \\
\hline i (age-16) $)^{3}$ & & & & 0.024105 & 0.001 & $<0.0001$ & & & \\
\hline i (age-18) $)^{3}$ & & & & -0.019613 & 0.001 & $<0.0001$ & & & \\
\hline i (age-18) & & & & 0.0000016876 & $2.79 \mathrm{E}-7$ & $<0.0001$ & & & \\
\hline i(age-15) $)^{3}$ & & & & & & & 0.055932 & 0.003 & $<0.0001$ \\
\hline i (age-16) & & & & & & & -0.050105 & 0.003 & $<0.0001$ \\
\hline \multirow[t]{3}{*}{ iage-16) $)^{4}$} & & & & & & & 0.0000025107 & 4.05E-7 & $<0.0001$ \\
\hline & \multirow{2}{*}{\multicolumn{3}{|c|}{$\begin{aligned} \mathrm{SD} & =1.17866 \\
\mathrm{R}^{2} & =64.1 \%\end{aligned}$}} & \multirow{2}{*}{\multicolumn{3}{|c|}{$\begin{aligned} \mathrm{SD} & =1.10048 \\
\mathrm{R}^{2} & =65.6 \%\end{aligned}$}} & \multirow{2}{*}{\multicolumn{3}{|c|}{$\begin{aligned} \mathrm{SD} & =1.2348 \\
\mathrm{R}^{2} & =64.2 \%\end{aligned}$}} \\
\hline & & & & & & & & & \\
\hline f(age, gender) & \multicolumn{3}{|c|}{ Model 2: Interaction, age terms not shown } & & & & & & \\
\hline Gender (f vs. m) & -0.26 & 0.05 & $<0.0001$ & & & & & & \\
\hline \multirow[t]{2}{*}{ Gender* ${ }_{i}$ age $(<20)$} & 0.63 & 0.07 & $<0.0001$ & & & & & & \\
\hline & \multicolumn{3}{|c|}{$\mathrm{R}^{2}=64.7 \%$} & & & & & & \\
\hline
\end{tabular}

Mean IGF-I $=[\mathrm{f}(\mathrm{age})]^{2.5} ;$ reference curves $=[\mathrm{f}(\mathrm{age})+\mathrm{kSD}]^{2.5}$ where $\mathrm{k}=0,1,2$. 
at least 80 years of age (fig. 1a; table 3: model 1a, no adjustment for gender).

When incorporating an interaction term between gender and age into the model, the data show a statistically significant difference in mean levels between males and females. The $\mathrm{p}$ value for both gender and the interaction term gender* ${ }_{i}($ age $<20)$ was $<0.0001$. $\mathrm{R}^{2}$ for the model was $64.7 \%$ (table 3: model 1b). Due to this significant effect of gender and different sizes of the standard deviations, we decided to fit two separate models, one for each gender. Both showed similar $\mathrm{R}^{2}, 65.6 \%$ for males and $64.2 \%$ for females (table 3 : model $1 \mathrm{~b}$ ). The implications of these models are shown in figure $1 \mathrm{~b}, \mathrm{c}$. Table 4 shows read values from figure 1 for ages 1 year up to $75-80$ for males and females as well as for the whole population. The model for males had an estimated mean peak of S-IGF-I at $382 \mu \mathrm{g} / \mathrm{l}$ around 16 years of age. The mean peak among girls was estimated to $410 \mu \mathrm{g} / \mathrm{l}$ at 14 years of age. The difference between fitted gender-specific means was around 20 the first 3 years of life. The difference was greatest

Table 4. S-IGF-I ( $\mu \mathrm{g} / \mathrm{l})$ reference ranges for the Nichols Advantage( at ages 1-19 years $(\mathbf{A})$ and 20 to $75-80$ years (B). Values were calculated from the fitted polynomial models (see Results section, fig. 1 and table 3)

\begin{tabular}{|c|c|c|c|c|c|c|c|c|c|c|c|c|c|c|c|c|c|c|c|}
\hline \multirow[t]{2}{*}{$\mathbf{A}$} & \multicolumn{19}{|c|}{ Age, years } \\
\hline & 1 & 2 & 3 & 4 & 5 & 6 & 7 & 8 & 9 & 10 & 11 & 12 & 13 & 14 & 15 & 16 & 17 & 18 & 19 \\
\hline \multicolumn{20}{|c|}{ Total (fig. 1a) } \\
\hline$+2 \mathrm{SD}$ & 154 & 151 & 159 & 176 & 203 & 239 & 284 & 336 & 395 & 457 & 518 & 572 & 614 & 638 & 639 & 615 & 581 & 548 & 519 \\
\hline$+1 \mathrm{SD}$ & 101 & 98 & 104 & 118 & 139 & 168 & 204 & 248 & 297 & 349 & 401 & 448 & 485 & 506 & 506 & 486 & 456 & 427 & 402 \\
\hline Mean & 60 & 58 & 63 & 73 & 89 & 111 & 140 & 175 & 215 & 259 & 302 & 342 & 373 & 391 & 391 & 374 & 348 & 324 & 303 \\
\hline$-1 \mathrm{SD}$ & 31 & 30 & 33 & 40 & 51 & 68 & 90 & 117 & 149 & 184 & 220 & 252 & 278 & 294 & 294 & 279 & 258 & 238 & 220 \\
\hline$-2 \mathrm{SD}$ & 13 & 12 & 14 & 18 & 26 & 37 & 52 & 72 & 96 & 124 & 152 & 179 & 200 & 212 & 213 & 201 & 183 & 167 & 153 \\
\hline \multicolumn{20}{|c|}{ Males (fig. 1b) } \\
\hline$+2 \mathrm{SD}$ & 136 & 133 & 138 & 152 & 173 & 203 & 240 & 285 & 336 & 392 & 449 & 504 & 552 & 588 & 608 & 608 & 586 & 554 & 524 \\
\hline$+1 \mathrm{SD}$ & 90 & 87 & 91 & 102 & 119 & 143 & 173 & 210 & 253 & 300 & 349 & 396 & 438 & 470 & 487 & 487 & 468 & 440 & 414 \\
\hline Mean & 54 & 53 & 55 & 63 & 76 & 95 & 119 & 149 & 184 & 223 & 264 & 304 & 340 & 367 & 382 & 382 & 365 & 341 & 319 \\
\hline$-1 \mathrm{SD}$ & 29 & 28 & 30 & 35 & 44 & 58 & 76 & 99 & 127 & 159 & 193 & 226 & 256 & 279 & 292 & 292 & 278 & 257 & 239 \\
\hline$-2 \mathrm{SD}$ & 13 & 12 & 13 & 16 & 22 & 31 & 44 & 62 & 83 & 107 & 134 & 162 & 186 & 205 & 216 & 216 & 204 & 187 & 172 \\
\hline \multicolumn{20}{|c|}{ Females (fig. 1c) } \\
\hline$+2 \mathrm{SD}$ & 178 & 175 & 184 & 205 & 235 & 276 & 327 & 386 & 450 & 515 & 577 & 629 & 665 & 678 & 663 & 622 & 582 & 546 & 515 \\
\hline$+1 \mathrm{SD}$ & 117 & 115 & 122 & 137 & 162 & 195 & 236 & 285 & 339 & 394 & 447 & 492 & 523 & 534 & 521 & 486 & 451 & 421 & 394 \\
\hline Mean & 70 & 69 & 74 & 86 & 104 & 130 & 163 & 202 & 246 & 292 & 336 & 374 & 401 & 410 & 399 & 369 & 340 & 314 & 292 \\
\hline$-1 \mathrm{SD}$ & 37 & 36 & 40 & 48 & 61 & 80 & 105 & 135 & 170 & 208 & 244 & 276 & 297 & 305 & 296 & 271 & 247 & 226 & 208 \\
\hline$-2 \mathrm{SD}$ & 16 & 15 & 17 & 22 & 31 & 44 & 62 & 84 & 111 & 140 & 169 & 194 & 212 & 219 & 211 & 191 & 171 & 154 & 140 \\
\hline \multirow[t]{2}{*}{ B } & \multicolumn{19}{|c|}{ Age in years } \\
\hline & 20 & 25 & 30 & 35 & 40 & 45 & 50 & 55 & 60 & 65 & 70 & $75-80$ & & & & & & & \\
\hline \multicolumn{20}{|c|}{ Total (fig. 1a) } \\
\hline$+2 \mathrm{SD}$ & 493 & 402 & 354 & 329 & 315 & 304 & 292 & 276 & 257 & 237 & 220 & 209 & & & & & & & \\
\hline$+1 \mathrm{SD}$ & 380 & 303 & 263 & 242 & 230 & 221 & 211 & 198 & 183 & 167 & 153 & 144 & & & & & & & \\
\hline Mean & 284 & 220 & 187 & 170 & 161 & 153 & 145 & 135 & 123 & 110 & 99 & 92 & & & & & & & \\
\hline$-1 \mathrm{SD}$ & 205 & 153 & 127 & 113 & 106 & 100 & 94 & 86 & 77 & 67 & 59 & 54 & & & & & & & \\
\hline$-2 \mathrm{SD}$ & 140 & 100 & 79 & 69 & 64 & 60 & 55 & 49 & 43 & 36 & 31 & 27 & & & & & & & \\
\hline \multicolumn{20}{|c|}{ Males (fig. 1b) } \\
\hline$+2 \mathrm{SD}$ & 497 & 402 & 350 & 323 & 307 & 296 & 285 & 271 & 255 & 238 & 223 & 213 & & & & & & & \\
\hline$+1 \mathrm{SD}$ & 391 & 309 & 265 & 242 & 228 & 219 & 210 & 199 & 186 & 172 & 159 & 151 & & & & & & & \\
\hline Mean & 299 & 230 & 194 & 174 & 163 & 156 & 148 & 139 & 129 & 118 & 108 & 101 & & & & & & & \\
\hline$-1 \mathrm{SD}$ & 222 & 165 & 135 & 120 & 111 & 105 & 99 & 92 & 84 & 75 & 68 & 63 & & & & & & & \\
\hline$-2 \mathrm{SD}$ & 158 & 112 & 89 & 77 & 70 & 66 & 61 & 56 & 50 & 44 & 38 & 35 & & & & & & & \\
\hline \multicolumn{20}{|c|}{ Females (fig. 1c) } \\
\hline$+2 \mathrm{SD}$ & 488 & 397 & 352 & 330 & 318 & 307 & 292 & 272 & 248 & 223 & 204 & 199 & & & & & & & \\
\hline$+1 \mathrm{SD}$ & 371 & 294 & 257 & 239 & 229 & 220 & 208 & 192 & 172 & 152 & 137 & 133 & & & & & & & \\
\hline Mean & 273 & 209 & 179 & 165 & 157 & 150 & 140 & 127 & 112 & 97 & 85 & 82 & & & & & & & \\
\hline$-1 \mathrm{SD}$ & 192 & 141 & 117 & 106 & 100 & 95 & 88 & 78 & 67 & 56 & 48 & 45 & & & & & & & \\
\hline$-2 \mathrm{SD}$ & 128 & 89 & 71 & 63 & 58 & 54 & 49 & 42 & 35 & 27 & 22 & 21 & & & & & & & \\
\hline
\end{tabular}


between 11 and 13 years when girls had fitted means that were around $70 \mu \mathrm{g} / 1$ higher. At ages above 20, males had 6-26 $\mu \mathrm{g} / \mathrm{l}$ higher mean values. The smallest between-gender differences were seen between 35 and 50 years of age. Moreover, the reference range was a bit broader for females compared to males, for a given age (tables 3, 4). Reference values outside the age range 0.5-80 years should be judged cautiously for all models.

The fitted curves in figure 1 represent mean $\pm \mathrm{kSD}$, calculated as $[\mathrm{f}(\mathrm{age}) \pm \mathrm{kSD}]^{2.5}, \mathrm{k}=0,1$ and 2 . The distribution of observed S-IGF-I values on reference SD intervals closely followed what is expected from the normal distribution (data not shown). In an additional analysis, the laboratory and population was incorporated into the age- and gender-adjusted model and showed a statistically significant effect $(\mathrm{p}<0.0001) . \mathrm{R}^{2}$ increased to about $68 \%$.

In the fitted random intercepts age- and genderadjusted model for laboratories/populations, laboratories/ populations 3 and 5 a showed significantly higher mean S-IGF-I measurements, whereas laboratories/populations $5 \mathrm{~b}$ and $6 \mathrm{a}$ were significantly lower. The other 4 laboratories/populations did not significantly deviate from the overall mean (table 5). The laboratories/populations with high values ( 3 and $5 a$ ) had mean values that were 20 $60 \mu \mathrm{g} / \mathrm{l}$ higher at population mean levels from 60 to $400 \mu \mathrm{g} / \mathrm{l}$. Laboratories 5 (subpopulation b) and 6 (subpopulation a) showed mean values at population mean levels of $100,150,200 \mu \mathrm{g} / 1$ that were around $27,35,42 \mu \mathrm{g} / 1$ lower.

Table 5. Estimates and t tests of laboratory- and population-specific deviations from the age- and gender-dependent population mean using a random intercept model

\begin{tabular}{lllll}
\hline Lab & $\begin{array}{l}\text { Deviation } \\
\text { estimate }\end{array}$ & SE & t value & $\operatorname{Pr}>|t|$ \\
\hline 1 & 0.008 & 0.201 & 0.04 & 0.969 \\
2 & 0.023 & 0.198 & 0.12 & 0.908 \\
3 & 0.569 & 0.204 & 2.79 & 0.005 \\
4 & 0.244 & 0.203 & 1.20 & 0.231 \\
$5 \mathrm{a}$ & 0.699 & 0.256 & 2.73 & 0.006 \\
$5 \mathrm{~b}$ & -0.744 & 0.205 & -3.63 & 0.0003 \\
$6 \mathrm{a}$ & -0.783 & 0.207 & -3.78 & 0.0002 \\
$6 \mathrm{~b}$ & -0.015 & 0.209 & -0.07 & 0.943 \\
\hline
\end{tabular}

$\mathrm{H}_{0}$ hypothesis is that laboratory/population deviations is normally distributed $\left(0, \sigma^{2}\right)$ around the population mean. The numbers $1-6$ indicate different laboratories, $\mathrm{a}$ and $\mathrm{b}$ indicate different populations measured in one laboratory.
A reference range was also calculated excluding the subpopulations $\mathrm{a}$ and $\mathrm{b}$ in laboratory 6 . Compared to the reference range based on the total population, the mean decreased by $2-6 \mu \mathrm{g} / \mathrm{l}$ depending on age but the SD on the IGF-I ${ }^{0.4}$ scale was practically unchanged (increased from 1.17866 to 1.18046$)$.

\section{Discussion}

In the present study, reference values for S-IGF-I have been established based on a large number of healthy subjects between 1 and $>80$ years of age. The objective of the study was to generate data for S-IGF-I in a large set of clinically well-characterized healthy subjects under conditions close to the normal routine situation, i.e. with inclusion of serum samples from different populations run in different laboratories over a long period of time. To achieve this, a multicenter approach including IGF-I measurements in six different laboratories over a period of more than 2 years was used. The polynomial fitting approach makes the reference values well suited for longterm monitoring of S-IGF-I levels by Nichols Advantage ${ }^{\circledR}$ system.

The long-term reproducibility, including five laboratories and six instruments, estimated as coefficient of variation $(\mathrm{CV})$ was clearly $<7 \%$. Based on published data on intra-individual S-IGF-I variations in healthy subjects, indicating a biological variation of CV about $14 \%$ [13, $14]$, an analytical system offering a total reproducibility of $\mathrm{CV}<7 \%$ seems well suited for long-term monitoring of S-IGF-I [15].

By having a number of laboratories with a common quality control procedure involved in the work to establish reference ranges for an analyte, it is possible to detect and eliminate systematic analytical errors in any of the laboratories before the reference samples are analyzed.

In children and adolescents, the present study confirms previous studies showing an age-related increase in SIGF-I levels during the prepubertal and early pubertal stages followed by a decrease in late puberty [16-19]. Peak S-IGF-I levels during puberty occurred at 14 years of age in girls and at 16 years of age in boys with slightly higher peak values in girls.

In adult subjects, our results show a steady decrease of S-IGF-I levels with age, which has already been demonstrated by other authors [20,21]. In addition to this wellknown age-dependent S-IGF-I decrease, this study strongly indicates a gender difference in the adult reference ranges with males having 6-26 $\mu \mathrm{g} / \mathrm{l}$ higher mean S-IGF-I 
values. The gender difference were smallest between 35 and 50 years of age. Moreover, the reference range for females were generally a bit broader compared to males. A possible explanation for these gender differences may be the effect of estrogen use in females which is well known to influence S-IGF-I levels [22, 23]. Nevertheless, these gender difference is small and, in consequence, the use of a common adult S-IGF-I reference range seems to be reasonable for clinical practice.

Another important finding of this study is that the mean values of some reference sample subgroups differed significantly from the total mean. This result obviously reflects the influence of several factors that could affect S-IGF-I levels, i.e. differences between populations with respect to genetic background or nutritional status, preanalytical influences like sample collection and storage, as well as differences between laboratories. The finding underlines the fact that selection of a representative refer- ence population is a delicate task and a big sample size, collected from different sources, reduce the risk of a nondesirable impact from a single or few subpopulations.

In conclusion, the present study establishes age- and sex-specific S-IGF-I reference values for a fully automated immunoassay system based on a large population of healthy subjects. It also demonstrates that the reference values may be used for Nichols Advantage systems in different laboratories provided that the bias between systems is low. To achieve this, the same calibrators should be used in the different systems and an efficient intra- and inter-laboratory control procedure should be established.

\section{Acknowledgements}

The authors thank Prof. Berdel and Dr. Fössing, Department of Pediatrics, Marienhospital Wesel, Germany, for providing serum samples from healthy children.

\section{References}

1 Consensus guidelines for the diagnosis and treatment of adults with growth hormone deficiency: Summary statement of the Growth Hormone Research Society Workshop on Adult Growth Hormone Deficiency. J Clin Endocrinol Metab 1998;83:379-381.

2 Consensus guidelines for the diagnosis and treatment of growth hormone $(\mathrm{GH})$ deficiency in childhood and adolescence: Summary statement of the GH Research Society. GH Research Society. J Clin Endocrinol Metab 2000; 85:3990-3993

3 Hilding A, Hall K, Wivall-Helleryd IL, Saaf M, Melin AL, Thoren M: Serum levels of insulinlike growth factor I in 152 patients with growth hormone deficiency, aged 19-82 years, in relation to those in healthy subjects. J Clin Endocrinol Metab 1999;84:2013-2019.

4 Drake WM, Howell SJ, Monson JP, Shalet SM: Optimizing GH therapy in adults and children. Endocr Rev 2001;22:425-450.

5 Peacey SR, Shalet SM: Insulin-like growth factor 1 measurement in diagnosis and management of acromegaly. Ann Clin Biochem 2001; 38:297-303.

6 Leung KC, Ho KK: Measurement of growth hormone, insulin-like growth factor I and their binding proteins: The clinical aspects. Clin Chim Acta 2001;313:119-123.

7 Chan JM, Stampfer MJ, Giovannucci E, Gann $\mathrm{PH}, \mathrm{Ma} \mathrm{J}$, Wilkinson $\mathrm{P}$, Hennekens $\mathrm{CH}$, Pollak $\mathrm{M}$ : Plasma insulin-like growth factor-I and prostate cancer risk: A prospective study. Science 1998;279:563-566.

8 Burroughs KD, Dunn SE, Barrett JC, Taylor JA: Insulin-like growth factor-I: A key regulator of human cancer risk? J Natl Cancer Inst 1999. 91:579-581.

9 Bang P: Valid measurements of total IGF concentrations in biological fluids: Recommenda- tions from the 3rd International Symposium on Insulin-Like Growth Factors. Eur J Endocrinol 1995; 132:338-339.

10 Ranke MB, Feldt-Rasmussen U, Bang P, Baxter RC, Camacho-Hubner C, Clemmons DR, Juul A, Orskov H, Strasburger CJ: How should insulin-like growth factor I be measured? A consensus statement. Horm Res 2001;55:106109.

11 Chestnut RE, Quarmby V: Evaluation of total IGF-I assay methods using samples from Type I and Type II diabetic patients. J Immunol Methods 2002;259:11-24.

12 Armitage P, Berry G, Matthews JNS: Statistical Methods in Medical Research, ed 4. Oxford, Blackwell Science, 2002.

13 De Boer H, van der Veen E: Guidelines for optimizing growth hormone replacement therapy in adults. Horm Res 1997;48:21-30.

14 Gelander L, Blum WF, Larsson L, Rosberg S, Albertsson-Wikland K: Monthly measurements of insulin-like growth factor I (IGF-I) and IGF-binding protein-3 in healthy prepubertal children: Characterization and relationship with growth. The 1-year growth study. Pediatr Res 1999;45:377-383.

15 Fraser CG: General strategies to set quality specifications for reliability performance characteristics. Scand J Clin Lab Invest 1999;59: 487-490.

16 Juul A, Holm K, Kastrup KW, Pedersen SA, Michaelsen KF, Scheike T, Rasmussen S, Muller J, Skakkebaek NE: Free insulin-like growth factor I serum levels in 1,430 healthy children and adults, and its diagnostic value in patients suspected of growth hormone deficiency. J Clin Endocrinol Metab 1997;82:2497-2502.

17 Andrade Olivie MA, Garcia-Mayor RV, Gonzalez Leston D, Rodriguez Sousa T, Segura Dominguez A, Alvarez-Novoa R, Antelo Corti- zas J: Serum insulin-like growth factor (IGF)binding protein-3 and IGF-I levels during childhood and adolescence. A cross-sectional study. Pediatr Res 1995;38:149-155.

18 Lofquist C, Andersson E, Gelander L, Rosberg $\mathrm{S}$, Blum WF, Albertsson-Wikland K: Reference values for IGF-I throughout childhood and adolescence: A model that accounts simultaneously for the effect of gender, age and puberty. J Clin Endocrinol Metab 2001;86:58705876 .

19 Silbergeld A, Litwin A, Bruchis S, Varsano I, Laron Z: Insulin-like growth factor I in healthy children, adolescents and adults as determined by a radioimmunoassay specific for the synthetic 53-70 peptide region. Clin Endocrinol (Oxf) 1986;25:67-74.

20 Strasburger CJ, Bidlingmaier M, Wu Z, Morrison KM: Normal values of insulin-like growth factor I and their clinical utility in adults. Horm Res 2001;55:100-105.

21 Ghigo E, Bellone J, Aimaretti G, Bellone S, Loche S, Cappa M, Bartolotta E, Dammacco F Camanni F: Reliability of provocative tests to assess growth hormone secretory status. Study in 472 normally growing children. J Clin Endocrinol Metab 1996;81:3323-3327.

22 Anderson SM, Wideman L, Patrie JT, Weltman A, Bowers CY, Veldhuis JD: $E_{2}$ supplementation selectively relieves GH's autonegative feedback on GH-releasing peptide-2-stimulated GH secretion. J Clin Endocrinol Metab 2001;86:5904-5911.

23 O'Sullivan AJ, Crampton LJ, Freund J, Ho KK: The route of estrogen replacement therapy confers divergent effects on substrate oxidation and body composition in postmenopausal women. J Clin Invest 1998;102:1035-1040. 